\title{
Recreación medieval en Percival e outras historias (1958) de X.L. Méndez Ferrín y en Irmán Rei Artur (1987) de C. González Reigosa
}

\author{
CaRmen Mejía Ruiz y M. 므 DEL Mar LóPez VAlero
}

Universidad Complutense de Madrid

El "Percival" de Méndez Ferrín es uno de las primeras narraciones que publicó el autor y que da nombre al conjunto de relatos publicados en 1958 con el título Percival e outras historias. Este libro de relatos, entre otros, hace que al autor se le encuadre en la llamada "Nova narrativa galega" por lo que supuso de ruptura con la narrativa anterior y por las innovaciones técnicas que abren nuevas vías a la narrativa posterior.

La materia de Bretaña está presente en la obra ferriniana tratada desde prismas diferentes a lo largo de su creación. Así, centrándonos en "Percival" podemos observar la presencia medieval en el relato y su posible confluencia con la obra de Carlos G. Reigosa.

El autor recrea, en un ambiente en el que la fantasía y la realidad se fusionan, las aventuras del mítico caballero medieval personificadas en un aristócrata del siglo XX.

Percival, en la primera aventura, denominada $O$ Leonlobisco, va cabalgando por el bosque y se encuentra con un monstruo, mitad lobo, mitad león, con el que se enfrenta. En $A$ loita no chao, como buen caballero andante, arremete contra un hombre que golpea a otro brutalmente. En $O$ namoro, tercera y última aventura, Percival, atraído por la música y por el murmullo que sale de un chalet, se oculta entre los invitados a una fiesta y se enamora de una joven. Estas aventuras responden a la estructura del relato, ya que la división en tres capítulos se relacionan estrechamente con las tres salidas de Percival. Estas salidas que narra el autor son, como dice la nota final del relato, una de las muchas aventuras de Percival: Pro ninguén sabe as vegadas que Percival saíu, nen as que sairá (Vigo: Galaxia, 1976. p. 28). Se puede decir que el relato queda abierto para que el lector lo continúe en cualquier momento.

Con esta forma de organizar la narración, Méndez Ferrín invita al lector a ser narrador de una historia que se remonta muchos siglos atrás. De la misma manera que en la Edad Media se transmitieron las leyendas bretonas, desde el 
año 679 en que Nunio, autor del sur de Gales, consideró como historias auténticas las batallas victoriosas del guerrero Arturo en su Historia Britonum, hasta el siglo XII en que Jean Bodel se refería en su Chanson de Saisnes a aquellos vanos y agradables cuentos de Bretaña, y Geoffrey de Monmouth que presentó la Materia de Bretaña como historia seria en su Libellus Merlini -la cual hay que considerar como la verdadera y primera inspiración de las novelas artúricas-, el bagaje cultural acumulado se ha transcrito a través de un mundo mágico de hadas, magos, reyes, caballeros y héroes legendarios ofrecidos al lector mediante una ingente cantidad de leyendas e historias célticas. Los paisajes de la vieja Irlanda, verdes, brumosos, cargados de una atmósfera propicia para la creación de cuentos y secretos druídicos tiene su reflejo más literal en las tierras y en las costas de Galicia.

La realidad y la fantasía forman parte del universo narrativo y complementan la estructura de la obra. La utilización de un tiempo real insertado en un tiempo imaginario contrapone el mundo real, mundo atractivo y lleno de múltiples posibilidades para el lector. El paso de un mundo a otro se va graduando en algunos momentos de la narración, pero los límites entre esos dos mundos no están claramente definidos en el transcurso del relato.

Encontramos que nuestro protagonista, Percival, es un noble que vive en una mansión con un jardín y rodeado de criados. El narrador, en tercera persona, refiere que la acción transcurre en pleno siglo $\mathrm{XX}$ por las referencias a inventos como la radio, los anuncios fluorescentes, los semáforos, o por las alusiones a las contemporáneas prendas de vestir:

Percival levantouse da cadeira, pechóu a radio, ollóu pola fenestra. A longa lúa íase perder ao lonxe entre semáforos roxos e verdes de anuncios fluorescentes (edi. cit. sup., p. 17).

Percival, dentro de este mundo real, se presenta como un personaje que se levanta de un sillón, apaga la radio, enciende un pitillo, mira a través de la ventana, hace gestos de asco y acaba por cerrarla. Esta descripción detallada de lo que hace nuestro personaje sirve para anticiparnos su rechazo de la realidad $y$, en cierta medida, manifestar su necesidad de huir de ella. La ventana es un recurso que el autor utiliza para patentizar la distancia entre esos dos mundos, además de ser el medio que le aísla del mundo exterior:

Zarróu a fenestra con forza e choeuna con empeño. Asín estaba ben illado da rúa. A fenestra ben pechada. (...) Entón ollouna e, co aceno de noxo adoitado, arretiróu da rúa as mentes e a visión e pechóucomo dixen-a fenestra (p. 17).

Desde ese plano de la realidad y con el anunciado deseo de huir de ella, el autor nos muestra el espacio del personaje en el que de nuevo se mezclan la realidad y la fantasía. La posible fusión de los mundos presentes en el relato se manifiesta en la descripción del entorno de Percival: 
A radio estaba doorosamente silandeira enriba dunha mesiña de bimbio. Por todo un lenzo de parede, esgarabellos e volvoretas espetados de longo alfiler daban un áer de coor e de morte. Longas espadas, eisóticas e partidas polo meio, xacían por todo o chao da estancia (p. 18).

La presentación de este peculiar espacio en el que se mueve Percival es un paso más en esa gradación hacia el mundo de la fantasía. En opinión de Camino Noia: a descrición deste tipo de escenario, decorado cos elementos familiares do uso doméstico xunto á dos obxectos propios dos cabaleiros medievais $e$ ás paredes cubertas de insectos disecados, prepáranos para os acontecementos que van suceder fóra da lóxica real ${ }^{1}$. La inserción de los dos mundos se refleja igualmente en la descripción del jardín de Percival. Un lugar afortunado, idílico, un lugar maravilloso:

Ninguén da terra e de fora puido ver atal maravilla. Era unha parcela sementada de herba e de árbores... Os árbores eran vellos, tanto eran como é o mundo (p. 18).

Pero tal paraíso que nos evoca un mundo fantástico también tiene:

unha casiña de tellóns e ouralita que fechaba un water, e tiña unha porta escangallada e podre de humedén (p. 18).

De nuevo la presencia del mundo real, e incluso la sugerencia solapada de que sólo fuera una invención de Percival:

Os árbores eran outro, erguían as súas copas poderosas cara un ceo verde que inventara Percival (p. 18).

Desde este momento, el paso de la realidad a la fantasía y de la fantasía a la realidad son constantes, hasta el punto de no saber al final del relato si Percival es un fantasma que acude puntualmente a su cita con la leyenda: pois decíame a criada que tódolos primeiros de xulio - tal día come hoxe-Percival resucita para namorar unha rapaza fremosa (p. 26); o si es producto de la imaginación de un aristócrata cansado y aburrido; o si no se trata de un personaje que acaba transformado por la lectura de los libros, al igual que Alonso Quijano acabó transformado en Don Quijote por la lectura de los libros de caballería.

Con el juego de la realidad y de la fantasía el lector se adentra en las tres aventuras de Percival, que se suceden de idéntica manera. Percival sale al jardín, se adentra en él y comienza la aventura, una vez acabada vuelve a casa y descansa.

' C. NOIA, A nova narrativa galega, Vigo, Galaxia, 1992, p. 72. 
¿Por qué recurre Méndez Ferrín al legendario Percival? Desde nuestra perspectiva el gran tema del relato es la formación de la leyenda como instrumento de salvación, es decir el continuo transcurrir de la ficción narrativa a través del tiempo y del espacio. O dicho de otra manera, el relato, como una herramienta de comunicación y de liberación que cualquiera puede utilizar. Una herramienta que se va construyendo a lo largo del tiempo, igual que los caballeros medievales van acercándose a su perfección a lo largo del viaje, paralelismo por el que se recrea la famosa leyenda de Percival.

En torno a este macrotema el autor añade una serie de temas secundarios. En primer lugar, la fantasía que utiliza para: a) abolir el mundo exterior. Una vez situados en el mundo de lo irreal y, por tanto, de los posible, b) denunciar esa realidad dando cuenta del mundo interno que la sustenta y, finalmente, c) dejar una puerta abierta a la esperanza. En segundo lugar, la violencia como una de las expresiones fundamentales del mundo interno. Una violencia brutal y gratuita, como cuando Percival, después de hablar con el Leonlobisco, lo mata sin más (p. 22); o absurda, como la lucha que Percival presencia en el suelo:

No meio do chao estaban dous homes. O primeiro home tiña debaixo dil ao segundo. $O$ pé do primeiro esmagáballe a testa ao segundo. $O$ de abaixo tiña un incensario co que incensaba ao de arriba. $O$ de arriba aspiraba o lume. $O$ de abaixo louvábao:

- Meu señor, meu dono, qué felicidade vos ter enriba de min!

$O$ de arriba calaba, e aínda lle pisaba a testa máis feramente (p. 24).

En tercer lugar, la alienación del ser humano, la pérdida de su identidad y de su dignidad, otro de los pilares de esa realidad que debe ser abolida, y finalmente, el amor que el autor recrea como un sentimiento apasionado e imposible.

La recreación de lo medieval en este relato se manifiesta mediante los motivos que utiliza el autor sacados directamente del ciclo bretón, aunque son numerosos los que nos remiten a otras culturas y a otras épocas.

Partiendo del nombre del protagonista, Percival, Méndez Ferrín recupera al caballero de la Tabla Redonda, que parte en busca del Santo Grial. La armadura del caballero medieval - espada, escudo, loriga, yelmo, grial- puesta en el presente sirve para alejarnos de la realidad. El bosque, recreación de la Yerma Floresta donde el Percival de Chrétien de Troyes tuvo su primer encuentro con el mundo de los caballeros y decidió su destino como caballero andante. Las salidas, aventuras caballerescas, de Percival son las distintas etapas que el caballero medieval debe superar en busca de su perfección, como parte fundamental del viaje iniciático. El Leonlobisco, un monstruo, constante de la mitología medieval, y uno de los muchos obstáculos con los que se tenían que enfrentar los caballeros en las narraciones de la Edad Media. Recordemos el dragón del Valle del Infierno que mató Tristán cuando estaba en Irlanda, la tie- 
rra de Iseo. Aunque el Leonlobisco no es tan fiero como el de C. de Troyes, sino más bien ingenuo e inocente, víctima fácil de la violencia de Percival. El autor en esta aventura hace una recreación de la actitud de algunos caballeros que tomaban las armas del vencido o su cabeza como muestra de su poder. Tristán, por ejemplo, se lleva como muestra del triunfo la lengua del dragón, mientras que Percival, una vez muerto el Leonlobisco, le arranca la piel y se la lleva a su criado:

\section{¡Ah! Toma ista pelica e manda facer unha alfombra pró teu carto (...) (p. 22).}

En A loita no chao Percival le dice a su criado antes de entrar en el bosque:

Dille a Fij e Meutre..., e ás outras criadas que se arretiren das fenestras, que me voy espir (p. 23).

Este motivo lo recoge el autor de las leyendas medievales y lo recrea. Concretamente, Lanzarote, el Caballero de la Carreta, se desnuda para cruzar el Puente de la espada, y no vuelve a vestir como un caballero hasta que no lo merece.

Hay un paralelismo entre lo que le sucede al Percival de C. de Troyes en el castillo del Grial y lo que le sucede a la doncella en la que se ha fijado nuestro Percival. El primero al no preguntar por el sentido de la copa y de la lanza, pierde el sentido de la búsqueda. La doncella por no preguntar a Percival quién es, lo acaba perdiendo. Cuando formula la pregunta ya es demasiado tarde:

E il meteuse no bosco bruante. Ela ficaba atrás co traxe revolto e o cabelo igoal.

- ¿Quén es tí? Berroulle outra ves.

- Eu son Percival - e a súa vos viña xa do meio do bosco. Eo vento ía rosmando da pola a pola:

- Eu son Percival...

- Eu son Percival... (p. 28).

El viento en la lírica de los trovadores se utiliza como un motivo que aviva el recuerdo de la amada o descubre los secretos del amor. En este relato se puede decir que el viento es el portador de la leyenda que atraviesa el tiempo y se pierde entre las ramas de los árboles del bosque.

Méndez Ferrín demuestra un gran dominio del contexto medieval, incluso en este breve relato se perciben técnicas narrativas que recuerdan las formas medievales de contar cuentos, como, por ejemplo, las interpelaciones al lectoroídor: ... saíu ao xardín. ¿Dixen ao xardín? (p. 19), o las repeticiones constan- 
tes en el diálogo entre Percival y el Leonlobisco: Falóu Percival... falóu calveiro... falóu Percival... falóu calveiro (p. 21).

Creemos que Percival puede ser trasunto de Méndez Ferrín, y desde esta perspectiva se percibe con claridad el gusto del autor por la tradición medieval y el deseo de que el lector también la descubra y pueda sumergirse, desde la fantasía, en ese mundo de ensueño y delirio. Así nos lo transmite el autor:

Iste conto escribino pra que o leitor seipa como se ten que comportar con Percival se o atopa, do xeito que eu o atopéi (p. 29).

Después de Percival e outras historias, Méndez Ferrín vuelve a retomar la Materia de Bretaña con la publicación de Amor de Artur ${ }^{2}$. Sin duda, la originalidad de este nuevo cuento sobre las aventuras y desventuras del rey Arturo radica en las propias intenciones del autor. No se trata únicamente de observar el renovamiento técnico, el profundo mensaje galleguista y el intenso realismo lírico que impregna toda su obra y que aparecen de nuevo aquí con energías renovadas. La peculiaridad planteada radica en la formulación de una innovadora e insólita alegoría fantástica del tema amoroso. Indudablemente, el tratamiento de las relaciones sexuales y afectivas de los personajes aparecen elaboradas desde una perspectiva inédita, singular y extravagante. En palabras del propio Méndez Ferrín:

$O$ que quixen facer foi un relato no que se estudiase unha relación amorosa pouco utilizada na literatura. Se vémo-lo erotismo na literatura, observaremos que sempre aparecen as mesmas situacións que, en realidade, son tópicos literarios, cando a vida erótica na vida mesma é moito máis variada (...) só se escribe literatura sobre outra literatura anterior. Entón ocorréuseme escribir sobre unha relación erótica excepcional na que unha infidelidade conxugal fose explicada polo grande amor que sentía o amante polo marido da amada.

É un pouco complicado, pero coido que na vida hai combinacións aínda máis complexas que non aparecen nunca na literatura. A xente escandalizase moito cando no cine aparece un amor homosexual ou cando aparece unha situación de sadismo e di: "iQue cousa máis nova!", cando na vida, me parece a min, que todo é bastante máis complicado. Pois ben, sobre a base dunha situación amorosa complexa escribín "Amor de Artur" 3.

2 En opinión de GonZález-MilláN y Fernández del Riego en 1982, año de la publicación de Amor de Artur, se observó una diversificación de los modelos narrativos que hicieron de esta nueva representación de la materia artúrica el best-seller de la década dentro de la producción literaria gallega. Xoán González-Millán, A narrativa galega actual (1975-1984). Unha historia social, Vigo, Xerais, 1996, p. 222; F. Fernández del Riego, Historia da Literatura, Biblioteca Básica da Cultura Galega, Vigo, Galaxia, 1984, p. 214.

${ }^{3}$ Xosé M. Salgado y Xoán-M. Casado, X.L. Méndez Ferrín, Barcelona, Sotelo Blanco Edicións, Realidade, 1989, pp. 246 y 247. 
Esta especial recreación de algunos de los motivos artúricos más puntuales en la Materia de Bretaña expresa de nuevo, como sustrato básico de la fabulación imaginativa de Méndez Ferrín, los ideales utópicos de Tagen Ata y su personal universo de elementos mitológicos ${ }^{4}$. Si en Perceval, tal y como se ha mencionado, Méndez Ferrín no se limitó a introducirse en la mecánica de los relatos de caballeros, sino que llevó a cabo una total recreación de la temática artúrica afín a sus inquietudes, en Amor de Artur ${ }^{5}$, el autor abre nuevas y sofisticadas posibilidades en el tratamiento de las leyendas del rey bretón desde que se iniciara en el cíclo artúrico, primero de la mano de Merlín y familia de Alvaro Cunqueiro y, posteriormente, con Rudyard Kipling y Xosé Luís Franco Grande que le incitó a seguir los pasos de la buena literatura de Gonzalo Rodríguez Mourullo y la literatura perfecta de Kafka ${ }^{6}$.

Fruto de esta comunión entre literatura, política y fantasía, inmersas en una Táboa Redonda galleguista, es el espíritu del autor de Retorno a Tagen Ata que nos ofrece una luminosa imagen de Reigosa, como fiel escudero del rey Arturo, cabalgando al lado del señor oculto e desexado, en el fervoroso prólogo que realiza para Irmán Rei Artur (Vigo, Xerais, 1987, pp. 21-25). Su apologética genealogia de la Materia de Bretaña convierten a Carlos G. Reigosa en un miembro más entre los creadores gallegos que forman parte del universo de inspirados escritores leales al rey Arturo de Bretaña y a su género de relatos. Desde Nunio a González Reigosa, pasando por Thomas Malory, Ramón Cabanillas, el propio Xosé Luís Méndez Ferrín, Álvaro Cunqueiro, John Steinbeck o Darío X. Cabana? la continuidad del tema artúrico, a lo largo de los siglos, se justifica entre los autores de origen gallego por los vínculos étnicos, culturales y espirituales que existen entre las tierras atlánticas. Vínculos ya esbozados desde la fructífera labor reivindicativa que iniciaron los hombres de la Xeración Nós, y su determinante "Teoría del Atlantismo"s.

En este sentido, es natural la tendencia de los autores a converger afines en los mismos intereses, en los mismos sueños y en los mismos esfuerzos literarios. Es lógica la identificación creativa que esta naturaleza común permite hacer de las personalidades gallegas como fuentes inagotables de la recreación

${ }^{4}$ La parábola política representada por TAGEN ATA expresa la contienda de la nueva conciencia galleguista radicalmente opuesta al culturalismo moderado de un viejo nacionalismo. VV.AA, Literatura Galega, Vigo, "Colectivo Seitura", Xerais, 1988, p. 409.

5 X.L. MÉNDEZ FERRIN, Amor de Artur e novos contos con Tagen Ata ao lonxe, Vigo, Edicións Xerais de Galicia, 1982.

${ }^{6}$ X.M. Salgado y X.M. CASADO, Op. cit., p. 201.

${ }^{7}$ Fundamentalmente con su relato $A$ invasión (1983) en el que utiliza la alegoría y la parábola para crear un mundo más sugerido que referido, a través de unos registros narrativos que se interrelacionan con las influencias de Méndez Ferrín, aludiendo a un mundo artúrico que articula su propia simbología nacional. X. GONZÁLEZ-MILLÁN, Op. cit. sup., pp. 278-279.

${ }^{8}$ Esta teoría defiende las huellas célticas comunes a bretones, normandos, irlandeses y gallegos, dentro de su naturaleza atlántica, potenciando así el papel que le corresponde a Galicia dentro de la cultura y de las letras universales. Isabel GARCía PIQUERAS, La Revista Nós y el vínculo atlántista, "Revista de Filología Románica", Memoria-Homenaje a Pedro Peira Soberón, n 14, vol. 2, (1997), Universidad Complutense de Madrid, pp. 143-149. 
de la temática artúrica. Así, Reigosa elabora un retrato de Méndez Ferrín donde se destaca, entre otros aspectos no menos interesantes de este orensano comprometido con la política y la literatura ${ }^{9}$, la múltiple personalidad de Méndez Ferrín como Cabaleiro da Táboa Redonda y su capacidad para crear un universo bretón, una Tagen Ata o Galicia, enriquecida con los sueños independientes de una pluralidad de personajes nacidos de sus herencias y sueños pancélticos ${ }^{10}$.

En esta línea de acontecimientos literarios galaicos, era imposible que Reigosa, este bretón de Pastoriza (Lugo), se sustrajera a la atracción que ejerce la Materia de Bretaña sobre la mayoría de los novelistas. En opinión de Anxo Tarrío, con Irmán Rei Artur, Reigosa retoma desde una nueva y original perspectiva el tema de los caballeros de la Tabla Redonda. Los tres relatos que componen el libro - A tentación de Lanzarote (Cantar sen xesta)", Amor de Merlín, A morte do Rei Artur (conforme á copia de Sir Thomas Malory)— son el resultado lógico de un pasado artúrico revitalizado, no exento de una dotación psicológica en sus personajes, levemente perceptible en las intenciones que lo provocaron inicialmente en el medievo atlántico.

La leyenda se reencarna en las necesidades del presente. Si en 1113 el guerrero del siglo VI, Artús, era ya innegablemente el rey de un mundo feérico, convertido en un guerrero durmiente cuyo regreso "mesiánico" se esperaba con certeza absoluta, en el mundo de Reigosa las raíces céltico-bretonas de su naturaleza galaica anuncian no sólo la creencia firme de Artur como sustrato etnográfico de su pueblo, sino que además lo utiliza como un arma histórica para enfrentarse a los invasores, para defender su identidad contra las interferencias impuestas. Si el alboroto de Bodmin ${ }^{12}$ fue seguido de una furiosa réplica por parte de los "creyentes" de Artur, las burlas anglosajonas narradas por el autor de Irmán Rei Artur obtuvieron su respuesta a través de las gestas resguardadas en la memoria:

¿Que xestas? Todas, xaora: As reais e as inventadas, as certas e as incertas, as de antano e as de onte, todas xuntas, desde que o neto dun

\footnotetext{
${ }^{9}$ Para MÉndez FerRín, Galicia es un cosmos independiente, soberano. Sus convicciones galleguistas entroncan con la profunda universalidad que ya defendieron los hombres de la Época Nós, y que aparecen retomadas por su contemporáneo Gonzalo Rodríguez Mourullo en sus Memorias de Tairi (1956). GonŹález-Millán, Op. cit., p. 343; A. TARrío VAREla, Literatura Gallega, Historia Crítica de la Literatura Hispánica, 28, Madrid, Taurus, 1988, p. 165 y 166.

${ }^{10}$ Carlos G. Reigosa, Ferrín: da pólvora ás magnolias, "O Correo Galego", Teatro do mundo, 10-III-1996. pp. 64-88.

"Este relato se había publicado dos años antes en el volumen correspondiente a 1985 de las narraciones que se premiaron en el $10^{\circ}$ Concurso Modesto R. Figueiredo, con el título Cantar sen xesta de Lanzarote do Lago, en A. TARRío VARELA, Literatura Galega. Aportacións a unha historia crítica. Vigo, Xerais, 1994, p. 443.

${ }^{12}$ Hacia mediados del primer cuarto del siglo XII, unos monjes de Laon visitaron Bodmin en Cornualles para llevar a cabo su colecta. Les fue mostrada la silla y el horno del rey Arturo. Los monjes se burlaron abiertamente del carácter sagrado del lugar y de la creencia de que Arturo regresaría para liberarlos. K. Briggs, Diccionario de las Hadas, Barcelona, Alejandría, 1992, p. 231.
} 
troiano chegara cos seus homes á deserta illa de Albión —só poboada daquela por algúns xigantes sen importancia-ata que os herdeiros do Rei Artur, moitos anos despois, guindaron na noite dos tempos todo un imperio de glorias e sabidurías hogano inimaxinables. É dicir, tódalas historias do mundo. E todas, as propias e as alleas, convertidas en bretonas para sempre... (edi. cit. sup., p. 31 ).

Para ello, Reigosa necesita romper de una forma definitiva la línea que separa la realidad de la ficción, de la misma forma en que Méndez Ferrín fractura su propia línea de realidad y fantasía. Es significativo que para el caso de Lanzarote utilice el mismo recurso que se destaca en el Percival ferriniano: la ventana, puerta hacia el mundo de la fantasía, hacia la aventura que arrebata al héroe de su propia realidad:

O xove Lanzarote adicaba o tempo de folganza a soñar. Asomado ás estreitas ventás da torre, ollaba embebecido a largacía chaira que nacía ó pé do castelo e se extendía, verdexante, ata o mar. Imaxinaba daquela, detrás da horizontal precisa que tracexaban as augas, as feraces terras da Bretaña insular (p. 44).

Indudablemente, al autor no le basta este paralelismo con Méndez Ferrín en las estructuras narrativas empleadas, ni puede limitarse a las correspondencias concordantes que se establecen entre ambos relatos. Reigosa precisa acercarse, de una parte a la producción internacional existente que contiene el mundo que pretende reflejar ${ }^{13}$, así como adoptar el cosmos del Santo Grial inventado en tierras del apóstol compostelano ${ }^{14}$, y de otra es imprescindible e inevitable que recurra a su propia tradición folclórica y a la mitología que encierra la herencia celta gallego-gaélica contenida en el pensamiento del autor $^{15}$.

Reigosa combina todas aquellas influencias que percibe desde fuera del ámbito gallego con una evidente preocupación por reflejar un pasado histórico-legendario común a la problemática reivindicativa de sus signos de identidad. Así, por tanto, dentro de la ficción fantástica que representa el juego artúrico se entremezclan las nuevas técnicas literarias que permiten ampliar el universo mítico, y reinterpretar la ficción legendaria en convergencia con las

${ }^{13}$ Desde la Historia regum Britanniae de G. de Monmouth, los relatos galeses Llyfr gwyn Rhydderch, Llyfr coch Hergest, y los cuentos caballerescos de C. de Troyes hasta la británica interpretación de Sir Thomas Malory, entre los más destacables. Mabinogion, ed. de Victoria Cirlot, Madrid, Ediciones Siruela, 1988, IX-XXI.

${ }^{14}$ Desde la lírica de los Cancioneros, las composiciones de Alfonso X el Sabio, el panceltismo romántista de Eduardo Pondal, Na noite estrelecida de Ramón CABAnILlas, Merlín y familia o As crónicas do Sochantre de Álvaro CUNQuEIRo, Memorias de Tains de Gonzalo Mourullo, hasta las citadas de Méndez Ferrín o Darío X. Cabana, entre otros.

${ }^{15}$ Sobre las concordancias entre la mitología y el folclore gallego e irlandés vid. R. SAINERO, La huella celta en España e Irlanda, Madrid, Akal, 1987. 
realidades contemporáneas del autor que las lleva a cabo dentro de un nuevo discurso ${ }^{16}$.

La existencia de unos parámetros establecidos a través del análisis de los contenidos narrativos del ciclo artúrico, tales como el ideal caballeresco, el amor cortés, el ideal estético y las representaciones mágico-maravillosas, se enriquecen con la presencia innovadora de las nuevas técnicas literarias que Reigosa utiliza con absoluto control, introduciendo concluyentes rupturas en la linealidad cronológica del relato a través de frecuentes avances y retrocesos temporales que determinan la resolución posterior de los acontecimientos; pone en juego, además de este determinante tratamiento del tiempo, un importante recurso psicológico utilizando monólogos interiores que abren al lector el mundo del subsconsciente, ya sea éste colectivo por el conjunto contextual que representa, ya sea individual por expresar los procesos mentales que influyen en el estado y la evolución del comportamiento del individuo. Si, por ejemplo, en las novelas artúricas, el lector realiza gran parte del trabajo deductivo del pensamiento intimista del personaje, el cual representa un modelo funcional y arquetípico de conducta, Reigosa explicita en profundas disertaciones, reales y constatables por la contemporaneidad de las deducciones a las que llega el personaje, la personalidad humana más introspectiva.

En este sentido, cabe cuestionarse cómo el autor puede alcanzar estos términos sin plantearse pautas de referencia que le conduzcan linealmente a la solución que busca; es decir, si opta por exponer aquellos deseos y pensamientos más íntimos de sus protagonistas, opta igualmente por diferenciar los elementos éticos y culturales que disocian la presentación de dichos personajes como modelos de recreación paradigmática. De esta forma, ante la ocupación física y cultural de un enemigo foráneo, Reigosa establece una lucha que se justifica con un pasado enriquecido históricamente. Para ello utiliza las bases de un concepto antropológico que diferencia étnicamente el yo del $t u ́$, el nosotros frente a los otros mediante el recuerdo de un pasado potencialmente fantástico y la presencia inmanente de un cuerpo de leyendas recreadas en la fértil imaginación de los ensueños pancélticos. Reigosa no discute si se trata de un pasado cierto o no, puesto que la propia lógica permite deducir que la presencia misma de un vacío que impide confirmar la realidad es, en sí misma, la que imposibilita negar su existencia. Ésta es precisamente la premisa que utiliza Reigosa para fracturar lo real de lo irreal, conformar un pasado de hazañas heroicas adaptadas y desarrolladas, y en ningún caso cuestionables.

En esta línea, Carlos G. Reigosa aporta su particular visión de algunos de los acontecimientos del ciclo artúrico más decisivos a la hora de establecer conclusiones sobre el devenir de los hechos que caracterizaron la vida de algu-

${ }^{16}$ Durante la década de los 60 aparecen dentro de las letras gallegas una generación de escritores, con formación universitaria, fuertemente conocedores e influenciados por W. FAULKNER, F. KAFKA, James JOYCE, el nouveau roman, etc., al tiempo que intentan introducir en la narrativa gallega los resortes técnicos de la novela extranjera. M. JusTo GIL, La literatura en lengua gallega, Madrid, Ed. Cincel, Madrid, 1990, p. 101. 
nos de los caballeros más insignes de la Tabla Redonda. Reinventa y reescribe episodios que entran directamente en el juego de los condicionamientos que mueven a un individuo a tomar decisiones que modifican el rumbo de los sucesos que han de derivar en la historia conocida, al margen por supuesto de lo que siempre se espera de ellos.

El autor de Pastoriza podría haber elegido cualquier hecho o personaje directamente relacionado con la Materia de Bretaña - la fecundación de Igraine, las peculiares relaciones de Artur y Morgana, la traición de Xenebra, la conquista de Excalibur, etc.--, sin embargo es determinante la elección que lleva a cabo, ya que representa el eje principal de todo el ciclo artúrico. Es decir, selecciona aquellos personajes - Lanzarote, Merlín y Artur-que configuran el epicentro sobre el que se desarrollan todas las tramas ficcionales de las leyendas originadas en torno a la figura del hijo de Úther Pendragón.

En A tentación de Lanzarote (cantar sen xesta), Lanzarote no se nos presenta como el caballero arquetípico, como el héroe superior que domina las leyes que rigen a la Humanidad y a la Naturaleza. Reigosa destruye el mito de la ficción y lo convierte en un hombre que, aún cumpliendo todos aquellos preceptos que obligan al caballero comprometido dentro del sistema medieval regido por los principios "dogmáticos" de la Orden de Caballería, reacciona y se conduce como un individuo no-especial, humano no-superior, un guerrero que se plantea dolorosamente las razones que le han llevado a ser lo que es y los motivos que le conducen a tomar determinadas posturas ante situaciones concretas. El mejor caballero de la Tabla Redonda es para Reigosa un ser abatido por la incertidumbre y vencido por sí mismo. Ésta es posiblemente la primera vez que Lanzarote, héroe por antonomasia, es vencido fuera del campo de batalla, y lo es precisamente de su propia mano.

La tentación no es por sí misma la causa de la tragedia que se desencadenará posteriormente, sino que es el primer germen de duda en el ánimo del caballero lo que provocará el resto de los tristes (y predestinados) acontecimientos que estructuran la leyenda. La duda es la causa que vence sobre todas las demás razones. La duda convierte a Lanzarote en un elemento mimético que ocupa una posición de equidad con respecto al lector y en relación directa con las leyes que rigen al resto de los mortales. El autor no hace que el caballero inicie su peregrinación a la búsqueda de aventuras que cumplan los principios de la Tabla Redonda: Non era un home que buscaba, senón un home que fuxía (p. 49); por el contrario, le dota de una incertidumbre que le obliga, por su noble naturaleza, a elegir entre permanecer al lado de aquellos a quien ama más profundamente - Artur y Xenebra - o autoimponerse un exilio, una huida que hacen de él un triste personaje en manos de indecisiones humanas casi insuperables.

La lealtad de Lanzarote hacia el ideal representado por Artur frente a la desgarradora pasión que siente por la reina Xenebra le obligan a iniciar un periplo que diluya todas sus dudas, porque se encuentra ante una disyuntiva que le convierte en el detonante trágico que habrá de desencadenar el final del sueño 
artúrico. Su viaje se escuda en una sencilla premisa: llevar allá donde fuere el objetivo primigenio de la Tabla Redonda, establecer la razón sobre la fuerza, la civilización sobre la oscuridad.

El caballero consigue salir invicto de todos los combates que se le presentan; no obstante será su encuentro con el gigante Tarquin el que le plantee la auténtica tentación. En este punto, Reigosa analiza sutilmente los entresijos psicológicos que confunden la razón de Lanzarote. Los caballeros de Artur defienden la justicia contra la fuerza, pero es precisamente mediante la fuerza con lo que Lanzarote impone el objetivo caballeresco que representa. Si éste es el medio a seguir, ¿qué le diferencia de sus adversarios?, ¿qué le hace distinto de aquellos a quienes juzga equivocados?, ¿quién puede hacerle entender que la lógica que emplea en la defensa de su ideal es la lógica correcta? Tarquin siembra dudas y tentaciones en un alma ya de por sí atormentada. Lanzarote vence con una fuerza superior al dialéctico gigante; no obstante será la predestinable intervención de Merlín la que disipe su incertidumbre y confirme su auténtica victoria sobre las proposiciones que le hiciera el adversario.

A vida sen todo iso non sería nada nin pagaría a pena. Porque o que verdadeiramente a fai fermosa é aquilo mesmo que a converte en maldita: A posibilidade de escoller, a liberdade de ser ou facer dunha ou doutra maneira... Fixéronnos para ser tentados a cotío; a tentación róldanos sempre. E nós témo-la posibilidade, e tamén a obriga, de escoller en cada ocasión. (p. 65)

Carlos G. Reigosa envuelve al lector dentro de los continuos cambios temporales, el pasado y el presente, que confluyen en la mente del caballero ${ }^{17}$. Así, pueden seguirse racionalmente los planteamientos más íntimos del protagonista. Lanzarote sabe que el tiempo transcurrido no ha borrado aquello que le empujó a un viaje de aventura; pero la certeza de un deber cumplido, de una opción correctamente tomada, la elección final entre ser un Caballero del Bien y un Caballero del Mal, cierran una etapa gris en la mentalidad del héroe, que si bien no puede superar las inevitables leyes de la Naturaleza ni impedir los avatares del destino, sabe, sin embargo, que ha cerrado un episodio que le devuelve al lugar de partida, habiendo cumplido uno de los principales preceptos de la aventura iniciática caballeresca: la superación de sí mismo.

En el segundo relato, $O$ Amor de Merlín, Reigosa lleva hasta sus últimas consecuencias las aventuras del mago enamorado. El personaje de Merlín no se aleja de la tradición artúrica que le presenta como poseedor de las facultades humanas del amor y el deseo, igual que cualquier otro hombre anónimo; sin embargo, lo que hace diferente esta historia es el tratamiento que se realiza

${ }^{17}$ El regreso al pasado sumergido en el ensueño: los duros entrenamientos de su tío Gwenbaus siendo muchacho; los recuerdos indelebles de la reina Elaine, su madre; el pasado histórico de su Benwick natal; los premonitorios vaticinios de Merlín; el esperado primer encuentro con Artur y la reina Xenebra, sus combates, rescates y victorias, etc. 
de ella. Es el desarrollo de una dialéctica entre el conocimiento de la Razón y el conocimiento del Amor. El medio utilizado para ello es el enfrentamiento entre Merlín, de la Fraga de Esmelle, y el mago Lagoo, de la Fraga de Grayne. Se trata de dos personajes refractarios, y al mismo tiempo equivalentes por la posición feérica que ocupan en la cadena artúrica del autor de Lugo.

El primero, reconocido, apreciado y temido en las Cortes del "mundo", es poseedor de un ingenio que mezcla, a partes iguales, el conocimiento y el saber -que Reigosa fusiona aquí con el control asumido de los poderes y de las ciencias mágicas - con los comportamientos que caracterizan a la naturaleza humana. Merlín representa un estado de conocimiento superior "contaminado" por los males terrenales derivados de un mundo cortesano complejo, heterogéneo y laberíntico. El segundo, por el contrario, un hechicero solitario, ermitaño, alejado de los "males sociales", hace uso de sus prerrogativas feéricas en la soledad que delimita las fronteras del mundo de los sentidos y el mundo de la razón. La dedicación prestada al Saber individualiza al hombre, le aísla de la comunidad a la que pertenece por origen y le convierte en un ser automarginado y hermético. Así pues, para uno, Merlín, el saber no debe quedar excluido ni mantenerse al margen de las delicias atormentadas del corazón humano; para el otro, Lagoo, ambas cosas son incompatibles y la una es o será siempre el arma destructora de la otra: el amor contra la razón, la sabiduría contra los sentidos.

Merlín ama a Nimue, a la que Reigosa convierte en una doncella de la mítica Dona do Lago, mientras que otras tradiciones la identifican con esta misma Dama, Guardiana de Excalibur. La joven Nimue - atolondrada y frívola, cortesana al fin y al cabo, según Lagoo- desencadena el trágico final de Merlín. ¿O no tan trágico, ni tal final? Ese es el juego que propone Reigosa a través de la mente deductiva y analítica de Lagoo y de las conversaciones que mantiene con su sobrino imaginario Tolon. Porque para Lagoo, Reigosa y demás lectores de la Materia de Bretaña, ¿no es Merlín mucho Merlín para acabar seducido, engañado y aniquilado por una muchacha, indiscutiblemente hermosa, huidiza, coqueta y, a juzgar por los hechos, un tanto falta de escrúpulos? ¿Cómo es posible que el hijo del ekupede Aquibez, dotado con el don profético de la clarividencia, no preveyera tan insólito final para él mismo, el más grande de los magos que han poblado la Tierra? ¿Qué le impide al autor crear ficción dentro de la ficción y proponernos alternativas tan fascinantes como las que hubieran podido salir de la mano del propio Merlín? Lo único que necesita para ello es sembrar la duda. La incertidumbre ya conocida que atacara a Lanzarote en la primera narración, es aquí por obra y magia del soberbio Lagoo, el instrumento, el artificio que nos deja hasta el final con la sospecha escéptica de esa posible muerte de Merlín y su resurrección en el caballero Pelleas, que acabará conquistando el corazón de Nimue y que aparece en su vida tan repentinamente como fundamentada es la duda de Lagoo.

Finalmente, tal y como el anciano mago le indicara al caballero Lanzarote, el hombre debe elegir para bien o para mal, y es la imaginación del lector la que hace la elección por él. Aquél que se deja tentar con las propuestas de Rei- 
gosa es el que, finalmente, decide la conclusión de la historia, al tiempo que, el autor, no permite que se dude de que todo lo ocurrido, incluso la elección del lector, sea fruto de la consciencia superior y de los planes, largo tiempo tramados, del mago Merlín.

Mención aparte merece el cuento final, A morte do rei Artur, capítulo narrado según la versión inglesa del siglo XVI de Sir Thomas Malory. La estructuración del relato en cinco escenas claramente diferenciadas - fragmentación ausente en los otros dos cuentos- aumenta, de una parte, la rapidez cronológica de los acontecimientos, y, de otra, la sensación de una constante movilidad espacial por parte de los personajes. La división episódica es percibida por el lector como la consecución, casi cinematográfica, de los últimos días del sueño artúrico, o lo que es lo mismo el fin del rey Artur de Bretaña, fotograma a fotograma. Es, probablemente, este peculiar tratamiento dentro del conjunto de cuentos que componen Irmán Rei Artur, lo que le hace tan especial. En los sucesivos microepisodios, Artur se enfrenta, en una guerra no deseada, con su amado Lanzarote; guerra que ha de abandonar para ir a luchar contra Mordred, su hijo y usurpador; ha de pactar una tregua que le hace cuestionarse la firmeza de sus principios e ideales más íntimos; y nos hace recordar las palabras del viejo mago en $O$ amor de Merlín, al decirle a su rey y señor:

- (...) Coidádevos vós, señor, que a amargura gaolpa xa cara á vosa derradeira hora.

- Saberei morrer, gran meigo, e no outro mundo loitaremos de volta no mesmo bando (p. 79).

Artur deja una guerra moralmente injusta para ir a combatir en una lucha suicida justificada en sus sueños de justicia bretona. El discurso de Artur, introducido a modo de conversación con un noble caballero-mensajero de sus huestes, es la culminación de las teorías, de los deseos, de los juegos llevados a término en Irmán Rei Artur:

E os nobres homes do meu reino, os meus fieis vasalos, tantas veces benenficiados polos meus favores, ¿que fixeron? (...) Foron enganados por eles mesmos... Enganounos ó comezo Mordred, pero ¿agora quen os engana? ¿Que fan agora que ven con claridade cales son os designios dese tolo? (...) Fan o que sempre fixeron: Someterse e agacharse diante do que manda, sen importarlles de certo se obedecen ordes xustas ou antollos dun tirano (...) As súas vidas non valen nada, nobre xoven; unhas vidas sen dignidade, ¿para que serven? (...) (p. 101).

Artur no se refiere a los simples hombres de la gleba, no habla de la soldadesca variable y avariciosa, traidora e infiel. Habla del pueblo bretón al que ha tratado de gobernar siempre según los ideales perfectos de justicia que defendieron los miembros de la Tabla Redonda; habla de esos mismos caba- 
lleros que defendían el ideal de xusticia, de verdade, de razón, los mismos lacaios que ahora sirven ciegamente las locuras de Mordred y han olvidado a su rey, a su patria, y al mundo que representaban. He aquí la herida más honda y sangrante de un Artur cansado, enfurecido y consciente de la proximidad de su última hora.

El episodio de la muerte del rey cargado de dinamismo, completo, lleno de la energía descriptiva y de la atractiva calidad resuelta de la naturaleza cronística medieval representa una vuelta al planteamiento inicial de $A$ tentación de Lanzarote. Se culmina el enfrentamiento entre Artur, Caballero del Bien, y Mordred, Caballero del Mal, padre e hijo, las dos caras de la misma moneda:

O Rei Artur avanzou coa lanza empuñada cara a Mordred. E Mordred, coa espada na man, dirixíuse cara ó Rei Artur. Unha e outra cara compoñian un mesmo xesto. Pai e fillo mostrábanse posuídos pola mesma cólera sen termo. E Lucan admirou apavorado o seu cruel parecido. Ambos combatentes encarnaban un mesmo personaxe. Quizais porque -pensou Lucan - tódolos homes, levados pola ira, representan un mesmo personaxe. (p. 124).

Los hombres iguales en la lucha, caballeros iracundos en el combate, Mordred y Artur, se convierten en símbolos divergentes de un mismo tiempo. Mordred cayó muerto entre el cúmulo de cadáveres enemigos, quedando su cuerpo en los restos de la batalla; pero Artur queda envuelto en el misterio: la desaparición de su cadáver, la barca de las hadas hacia Avalón, la espera de su regreso... Reigosa le devuelve al pueblo la conciencia artúrica porque el rey más grande de los reyes:

Ausente por mor das fatigas desta vida, volverá moi axiña. Porque o mundo cada vez seméllase máis a como pouco antes de el chegar (p. 126).

Dentro del macrotema heroico-medieval, la Materia de Bretaña, que el autor de Pastoriza recrea, se utiliza mecánicamente la misma fórmula a lo largo de los tres relatos: emparejar a los personajes por binomios afines y contrapuestos que desarrollan la acción física y racional dentro de las atmósferas, no creadas por Reigosa, sino tomadas prestadas de la tradición. Así, se observa el elemento dual principal entre Lanzarote y Tarquin, Lanzarote y Merlín, Merlín y Nimue, Merlín y Lagoo, Lagoo y Tolon, Artur y su mensajero, Artur y Galván, Artur y Mordred... Estos son los personajes que Reigosa utiliza para desarrollar los motivos paradigmáticos de la materia artúrica. El empleo de estos motivos, que bien podrían ser denominados clasificables y reconocibles, no impide que el autor gallego realice ciertos "guiños" anacrónicos al lector, fracturando de nuevo así la realidad y la ficción, y la ficción dentro de la fantasía. Ejemplo característico de este recurso es, entre otros, la mención de la posible reclusión del mago Lagoo en unha casa de saúde de increíble existencia para la época (p. 95). Esta presentación de dos planos temporales, la realidad actual 
y el pasado legendario, tiene, como ya se ha observado, su antecedente más inmediato en el Perceval de Méndez Ferrín y sus interrelaciones entre la cotidianeidad del autor y las coordenadas temporales propias del ciclo artúrico.

La libertad que Reigosa disfruta para crear la fantasía y modificar la leyenda pueden inducir al lector a identificar símbolos o signos referentes, conscientes o no, pero de naturaleza real que contribuyen en la elaboración de situaciones auténticas, mundos posibles dentro de cuentos históricos. Esta tendencia a la verosimilitud trágica bien puede observarse en el caso del gigante Tarquin, en A tentación de Lanzarote. El adversario de Lanzarote representa la fuerza bruta, la imposición de los fuertes sobre los débiles, la tiranía del poder. ¿Qué puede impedir al lector identificarlo con la naturaleza despótica de Tarquino el Soberbio, séptimo y último rey de los Tarquinos, expulsado en el 579 a.C. de Roma? El paralelismo es tan fácil como inevitable, a la sazón de que es el nombre no céltico más inmediatamente reconocible dentro de los relatos.

Por otra parte, son destacables numerosos motivos temáticos medievales. En el caso de $A$ tentación de Lanzarote existe una evidente presencia de la aventura caballeresca, propiciada por móviles íntimos, pero aventura al fin y al cabo. En estas hazañas se desenvuelve el ideal caballeresco. Por un lado, Reigosa presenta la aventura como una herencia directa de la Materia de Bretaña originaria; aventura que consta de un proceso de iniciación, desarrollo y culminación alterado por el juego cronológico mencionado anteriormente. El periplo caballeresco conlleva una serie de representaciones tanto figurativas como reales del mundo en que el autor sumerge a los personajes. La aventura, que indica un desplazamiento espacial y temporal, enmarca todos los puntos de referencia a los que la sociedad del momento alude a través del comportamiento de los protagonistas. La apreciación de la fama del caballero -que precede a Lanzarote en su llegada a Camelot primero, y a Caerleon despuésse explica mediante el entroncamiento cultural de la materia artúrica y de la materia épico-carolingia. Lo que tiene de guerrero y belicista el personaje, a medida que se desarrollan sus combates, aparece ligado dentro del denso ambiente heróico al concepto de fama o de honor, en una permanente necesidad de respirar el clima de la caballería, siempre elitista, que sirve al autor para conocer su presente y perpetuar su pasado en la búsqueda de fundamentos que revelen el significado de su conciencia histórica, lo que no le impide atormentar psicológicamente a sus personajes como a cualquier protagonista mortal y novelado.

La pluralidad y la variedad temática caracterizan la presencia de unidades expresivas, de motivos particulares. Es precisamente esta multipresencia la que facilita el desarrollo de la acción, o de las acciones de los relatos. Reigosa recurre a la consolidación de las cualidades del caballero como elementos arquetípicos sobre las que puede estructurar la psicología de sus personajes. Lanzarote, Artur, Galván o Pelleas se identifican con la prudencia, el valor, la generosidad de espíritu, el sentido del honor; son íntegros, leales, inteligentes, fieles a su palabra, a su ley y a su rey, fieles a su fe; igualmente sienten cólera, rabia y odio, cualidades que heredan de la psicología del héroe reflejado en las 
gestas. Reigosa les dota también de sentido del humor, sobre la mentalidad de Tarquin, Lanzarote se permite pensar que a súa filosofía era tan elemental que definila en máis dunha frase sería exceso (p. 51) y rompe conceptos incluso incuestionables en la mente del enemigo: el hecho de que Mordred cuestione la palabra de su padre, quebrando así todo el sistema inamovible de los esquemas de la Caballería:

Non había dúbida de que Mordred non se fiaba del. E o Rei Artur sentiu dor por isto. Mordred negáballe tamén o que ningún outro contendente lle negara antes: Que era un monarca que cumpría sempre requintadamente os seus compromisos. Porque o Rei Artur de Bretaña tivera para todos, ó longo da súa vida, unha soa palabra: Unha palabra de honra. (p. 120).

Otros de los principios reiterativos a los que recurre el autor es la descripción estética de sus personajes. Si en el pasado literario de la materia artúrica los caballeros y las damas vinculados a la corte y relacionados con las aventuras iniciáticas de los protagonistas eran en sí mismos modelos estéticos de belleza perfecta no cuestionables, Reigosa se permite la licencia de semialterar este ideal estético, quizá en el caso más llamativo, el de Lanzarote:

¿Non fora daquela cando descubrira que era un rapazolo pouco agraciado, máis ben feo, cunha expresión entre enfeitizada, cándida e inxenua? Aunque isto non era doado de admitir ós quince anos (...) Desde o primeiro momento tivera por certo que a súa beleza ou fealdade non cambiaban nada na hora do combate; eran xa que logo, algo irrelevante e inxel, nin sequera accesorio. (p. 47).

Por el contrario, en cuanto al físico de las damas se refiere, éstas encarnan la gracia, la belleza, la ternura, todas las virtudes que ha de poseer la figura femenina de su contexto social. En la Edad Media existe una poderosa corriente a favor del carácter estético de todos los placeres sensibles, placeres que se traducen no sólo en la belleza del ideal femenino, sino también en las altas cualidades espirituales de los personajes. Esta estética vital es el resultado de la proporción exacta entre una necesidad y una satisfacción, de manera que todos los caracteres puedan converger en un orden perfecto donde el conjunto de los elementos se interrelacionan armónicamente ${ }^{18}$. Tales son los casos que pueden apreciarse en las figuras de la sublime reina Xenebra o de la joven doncella Nimue.

En otro sentido, Reigosa recrea una atmósfera derivada de la tradición iniciada ya en los relatos de C. de Troyes. En primer lugar, se impone psicológicamente la elaboración mental de un espacio contextualmente favorable, un

${ }^{18}$ Edgar de Bruyne, La estética de la Edad Media. Madrid, La balsa de la Medusa, Visor, 1988, pp. 143 y ss. 
hábitat propicio para el desarrollo de la acción, este espacio es a fraga, el bosque, y los elementos que lo conforman: los árboles, las fuentes, los animales, los seres adscritos al submundo céltico y las personificaciones naturales, siempre en la línea de lo real y lo maravilloso, de los humano y lo feérico. Reigosa toma la simbología del bosque de su propia tradición céltica y de los mitos desarrollados por Méndez Ferrín en su tratamiento de la Materia de Bretaña en Perceval, en Retorno a Tagen Ata, y en Amor de Artur, básicamente ${ }^{19}$. Los fuertes soportes célticos constantes en las leyendas artúricas -Floresta de Chaira, Pazo de Miranda, Chaira de Barham, Costa de Dover, Fraga de Grayne, Fraga de Esmelle, Campas Cordeiras, Costa Armoricana, etc.- se entremezclan en una fusión mítica con los entes clásicos más cognoscibles --Deus, Demo, Cupido, Guerra Romana, Galia, Festas de Pentecostés, Domingo de Trinidade, etc.-.

La aparición amalgamada de estos motivos contribuye a crear un ambiente predispositivo para la naturaleza fantástica del ciclo artúrico recreado por Reigosa. Los maravilloso, lo sobrenatural, lo mágico, lo simbólico remiten a la facultad creativa de los mundos ficcionales ${ }^{20}$. Se trata de imágenes-resorte que integran lo imprevisible en los relatos: los gigantes Carados y Tarquin a los que se enfrenta Lanzarote, partes integrantes de un enemigo social amenazador, al tiempo que símbolos individualizados de la incapacidad congénita para comprender lo que representa el ideal caballeresco; los sueños como armas decodificadoras de la realidad revelada del héroe o como instrumento enmascarador de la predestinación final de la doncella de la Dona do Lago; la fantástica magia derrochada, real e inventada, por Merlín en sus intentos de seducir a Nimue; el surrealista detalle del chío dun paxariño nun campo con case douscentos mil homes en pe de guerra (p. 119), etc.

De igual forma, se reproducen nítidamente lo que Victoria Cirlot ha denominado escenas de terror ${ }^{21}$. En las acciones bélicas, en los encuentros desafortunados con el enemigo, en lo imprevisible de los relatos, la sugestión del miedo, o en su defecto la ausencia del mismo, y la sugestión cruenta que percibe el lector a través de la sangre, constituyen fenómenos dependientes dentro de la línea articulada del argumento general de la materia de Bretaña. La sugestión activa con que los diferentes hechos pueden sorprender al lector, casi tanto como a algunos de los personajes son los incidentes no previstos, los episodios excepcionales, accidentales o repentinos, el conocimiento del hecho previsible frente a la incógnita de su resolución final abren un doble plano que hace contrastar el mundo sensible de la aventura conocida con el mundo suprasensible

${ }^{19}$ A fraga, el bosque, aparece bipolarizado figuradamente en dos planos: simbolo de libertad y de felicidad, especie de Paraíso Original. cuyo recuerdo y búsqueda mueven a menudo a los personajes; la fantasía, utilizada en función del misterio y del enigma, pero también como reducto de liberación para el hombre en general y, en particular, para el hombre sometido a los abusos, al oscurantismo y a la represión del pensamiento por parte del poder. A. Tarrío Varela (1988), op cit., p. 167.

${ }^{20}$ A. SORIA, Sobre la fantasía ibérica medieval y sus posibles rasgos autóctonos en "Literatura y Fantasía en la Edad Media", ed. de J. PAREDES, Universidad de Granada. Granada, 1989, pp. 84.

21 V. CiRLot, Escenas de terror en la literatura artúrica, en ed. de J. PAREDES, op. cit., p. 190. 
de la imaginación. Así, el temor es aniquilado por las supremas virtudes caballerescas de las que gozan Artur y Lanzarote, el valor y el ideal de justicia, y aunque esperado por el lector, no por ello menos inquietante en el desarrollo de la escena. La sugestión de la sangre derramada en el castigo físico del combate o de la batalla se muestra como una expresión descriptiva, casi plástica, pictórica, de la despiadada y sanguinaria realidad caballeresca. La pérdida del líquido vital configura la idea sensitiva que contribuye a elaborar la atmósfera mítica de las pasiones liberadas ante el dolor y la muerte.

A loita, intensa, furiosa, destemida, durou máis dunha hora. Ó cabo deste tempo, un sobranceiro golpe do paladín do Rei Artur afundou o elmo do adversario e esmagoulle o cráneo. Unha vez no chan, o cabaleiro de Benwick cortoulle a cabeza. (p. 52).

(Mordred) na súa obcecación de fera malferida, só matinou na forma de atraer ó Rei Artur e situalo a unha distancia que atinxira a súa espada. Para logralo, tirou para si da lanza que o atravesaba e incrustouse nela ata a mesma arandela que gorecía a man que a empuñaba. O Rei Artur, arrastrado por esta forza e incapaz de solta-la arma do seu inimigo, descoidou a súa propia garda e nada fixo —ou nada quixo facer - por dete-lo golpe da espada de Mordred. Este, coas forzas que lle restaban concentradas nas mans en que brandía a arma, atravesoulle o elmo e feriuno de moita gravidade no cráneo (p. 125).

En fragmentos como estos, el autor se deleita en la descripción del sufrimiento dentro de los límites del mundo físico, provocando la imaginación visual del lector, en las escenas de la destrucción de la materia, de la crueldad consciente de la tortura al asestar el golpe y del irremediable dolor de la muerte.

Reigosa, conocedor de su propia consciencia cultural y de las significativas improntas dejadas por sus antecesores en la materia literaria, aúna, como heredero de una larga lucha reivindicativa por la idiosincrasia propia de Galicia, el mundo mágico de Cunqueiro con el realismo mítico de Anxel Fole o Xosé Neira Vilas, y fusiona el realismo social, presente en la obra de Eduardo Blanco Amor, con la innovadora presencia de las nuevas narrativas de Gonzalo Rodríguez Mourullo, Carlos Casares, Darío X. Cabana o Xosé Luís Méndez Ferrín. Por tanto, la valiente iniciativa de Reigosa para introducirse en una temática tan respetada por la tradición, tan admirada por la fantasía imaginativa de los hombres y tan necesaria para constatar la firmeza de las valoraciones emocionales que le son inherentes a la mentalidad gallego-céltica, no puede verse desligada de la poderosa presencia de los protagonistas literarios que, con anterioridad a él, sucumbieron a los encantamientos de la corte artúrica, evidenciando así que, con paso firme, la literatura gallega se fortalece progresivamente cuanto más indaga y muestra sus raíces etno-culturales dando, a la luz de las editoriales, relatos y novelas que no tienen que demostrar que existe una identidad galaica propia, sino que la expone generosamente, para que el resto de la comunidad internacional participe de ella. 
Detrás de la estrategia narrativa de recrear lo medieval, estos relatos ofrecen interpretaciones de tipo social y político; no obstante, nuestro objetivo ha sido desentrañar los recursos utilizados por los autores para hacer llegar a los lectores una leyenda del pasado modernizada. 